\title{
ROLA POGODY W NARRACJI O DRUGIEJ WOJNIE PUNICKIEJ
}

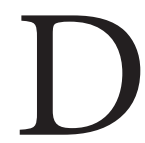

ruga wojna punicka zajmuje w historiografii rzymskiej szczególne miejsce - była to długa wojna $\mathrm{z}$ trudnym przeciwnikiem, obfitująca w początkowe klęski wojska rzymskiego. W czasie tych wieloletnich zmagań pogoda odgrywała znaczącą rolę - historycy antyczni przekazali nam kilka relacji o przeszkadzającej armii kartagińskiej pogodzie. Najbardziej znaną relacją jest oczywiście ta o próbie zdobycia Rzymu w 211 r. p.n.e. Ale - jak wiemy - były także momenty, w których pogoda sprzyjała Hannibalowi, między innymi w czasie bitwy pod Kannami w 216 r. p.n.e. Innym ważnym aspektem jest włączenie elementów meteorologicznych do narracji, jak zrobił to Florus, posługując się meteorologiczną metaforyką bitew.

W opisie początkowych lat zmagań kartagińsko-rzymskich Liwiusz w Ab Urbe Condita odnotowuje tak zwane prodigia ${ }^{1}$, czyli - jak je trafnie charakteryzuje Miron Wolny - „zwykłe wydarzenia poddane procesowi koloryzacji, czyli wyolbrzymienia [...] w celu poddania ich odpowiedniej interpretacji religijnej" 2 . To właśnie interpretacja nadaje im ową niezwykłość - czy też (według Wolnego) „cudowność” 3 . Są one odbiciem narastającej w Rzymie atmosfery strachu wywołanej szybkością ataku kartagińskiego oraz początkowymi klęskami Rzymian nad Ticynusem, Trebią czy Jeziorem Trazymeńskim. Sam Liwiusz ${ }^{4}$, opisując prodigia

${ }^{1}$ Całościowe opracowanie tematyki prodigiów wraz ze źródłami oraz listą wszystkich znaków wróżebnych zawartą w Appendix A: Index of prodigies: B. MACBAIN, Prodigy and expiation: a study in religion and politics in Republican Rome, Bruxelles 1982.

2 M. Wolny, Hannibal w Italii (218-217 p.n.e.). Studia nad uwarunkowaniami początkowych sukcesów kartagińskich, Olsztyn 2007, s. 270.

${ }^{3}$ Ibidem.

${ }^{4}$ Niestety, Juliusz Obsequens w swoim zależnym od Liwiusza dziele Liber prodigiorum opisuje zjawiska pojawiające się już po zakończeniu drugiej wojny punickiej - mianowicie w latach 
roku 218 p.n.e., tłumaczy je tak: „W Rzymie lub w okolicy wiele tej zimy pojawiło się znaków wróżebnych czy też - jak to zwykle bywa, gdy ludzie raz ulegną lękowi religijnemu - wiele zameldowano i łatwo w nie uwierzono"s, a w innym miejscu charakteryzuje je jako „złudzenia oczu czy uszu, wzięte za prawdę"6.

Prodigia można podzielić na zoologiczne, botaniczne, znaki „cudowne”, topograficzne czy też pogodowe właśnie ${ }^{7}$. Do tych ostatnich zaliczyć należy uderzenie piorunów w świątynię Nadziei przy forum Olitorium ${ }^{8}$, deszcz kamienny w Picenum $^{9}$ czy fatamorganę - pojawienie się na niebie światła $\mathrm{w}$ kształcie okrętó ${ }^{10}$ w 218 r. p.n.e.; w roku następnym ponownie deszcz kamienny na Awentynie oraz $\mathrm{w}$ Arycji11 ${ }^{11}$ a także piorun, który zabił kilku ludzi na drodze pod sklepieniem koło Pola Marsowego ${ }^{12}$. W 216 r. p.n.e. odnotowano między innymi powtórzenie kamiennego deszczu koło świątyni Junony-Wybawicielki w Lanuwium ${ }^{13}$, z tego

190-11 p.n.e. Prodigia odnotowują także inni rzymscy historycy: annaliści, Salustiusz i Tacyt. S. Papaionnnou, Omens and Miracles: Interpreting Miraculous Narratives in Roman Historiography, [w:] Recognizing Miracles in Antiquity and Beyond, ed. M. Gerolemou, Berlin-Boston 2018, s. 85-110; R. Garland, Miracles in the Greek and Roman World, [w:] The Cambridge Companion to Miracles, ed. G.H. Twelftree, Cambridge 2011, s. 75-94; W. Den Boer, Private Morality in Greece and Rome: Some Historical Aspects, Leiden 1979, s. 93; E. Rawson, Prodigy Lists and the Use of Annales Maximi, CQ 1971, vol. 21, s. 158-169; J.A. NorTh, Religion and Politics. From Republic to Principate, JRS 1986, vol. 76, s. 251-259.

${ }^{5}$ Liv. 21, 62, 1: Romae aut circa urbem multa ea hieme prodigia facta aut, quod evenire solet motis semel in religionem animis, multa nuntiata et temere credita sunt [...] [tłum. M. BRożeK].

${ }^{6}$ Liv. 24, 44, 7: [alia] ludibria oculorum auriumque credita pro veris [tłum. M. BrożEK]. W literaturze przedmiotu istnieje dyskusja nad stosunkiem Liwiusza do przejawów religii rzymskiej. Nie uwzględniam tu argumentów dotyczących stosunku Liwiusza do możliwych postaw wobec religii (a więc wiary i sceptycyzmu), zarówno dotyczących interpretacji historycznej oraz religijnej, prezentacji samych prodigiów - ich wyboru, jak i strategii językowych (używanie przez Liwiusza oratio obliqua oraz zwrotów wprowadzających dystans, jak videri czy velut, w ich opisach). J. ScHeID, Livy and Religion, [w:] A Companion to Livy, ed. B. Mineo, Chichester 2015, s. 78-89; J.P. Davies, Rome's Religious History. Livy, Tacitus and Ammianus on their Gods, Cambridge 2004, s. 17-19, 21-62; S. ŚnieżEwski, Koncepcja historii w Ab Urbe Condita Liwiusza, Kraków 2000, s. 28-31.

${ }^{7}$ R. Bloch, Les Prodiges dans l'Antiquité classique (Grèce, Étrurie et Rome), Paris 1963. O znakach innego rodzaju, takich jak narodziny hermafrodyty czy bliźniąt syjamskich, pisze W. DEN BoER, Private Morality in Greece and Rome..., s. 95 sqq., a do tego typu znaków wieszczych należy zaliczyć także okrzyki wydawane przez niemowlęta i dzieci w łonie matki, zmianę kobiety w mężczyznę itp. Cf. Liv. 24, 10, 10.

${ }^{8}$ Liv. 21, 62, 4: et aedem Spei, quae est in foro holitorio, fulmine ictam.

${ }^{9}$ Liv. 21, 62, 5: in Piceno lapidibus pluisse.

${ }^{10}$ Liv. 21, 62, 4: et navium speciem de caelo adfulsisse.

${ }^{11}$ Liv. 22, 36, 7: Nam et Romae in Aventino et Ariciae nuntiatum errat sub idem tempus lapidibus pluisse.

${ }^{12}$ Liv. 22, 36, 8: et in via fornicata, quae ad Campum errat, aliquot homines de caelo tacti axanimatique fuerant.

${ }^{13}$ Liv. 23, 31, 15: [signa Lanuvi ad Iunonis Sospitae cruore manavere] lapidibusque circa id templum pluit, [...]. 
powodu urządzono „jak zwykle, dziewięciodniowe ofiary przebłagalne”14. Liwiusz, opisując rok 215 p.n.e., odnotowuje: „Znaków wróżebnych tego roku zgłoszono dużo. Bo im więcej wierzyli w nie prości i religijni ludzie, tym więcej ich zgłaszano"15. Wśród prodigiów tego roku zapisał fatamorganę w Hadrii, gdzie widziano na niebie ołtarz i dokoła niego postacie ludzkie w lśniąco białych szatach $^{16}$, opady deszczu z kredą w Kales i krwi w Rzymie na Placu Wolim ${ }^{17}$ oraz serię piorunów uderzających w atrium publiczne na Kapitolu, świątynię Wulkana na Polu Marsowym, zamek w Sabinum, drogę publiczną, mur i bramę w Gabiach ${ }^{18}$. W 214 r. p.n.e. piorun uderza w mur i bramę w Kajecie oraz w świątynię Jowisza w Arycji ${ }^{19}$. Niezwykłe apogeum prodigiów pogodowych następuje jednak w roku 213 p.n.e.:

Były straszne burze. Na Górze Albańskiej przez dwa dni padał bez przerwy deszcz kamienny. W wiele obiektów uderzyły pioruny. Na Kapitolu w dwie świątynie. W obozie powyżej Suessuli w wał obozowy w wielu miejscach, przy czym zabiło dwóch strażników. W Kumach w mury i niektóre wieże obronne, w które piorun nie tylko uderzył, ale nawet je strącił. W Reate widziano latający olbrzymi kamień, słońce czerwone bardziej niż zazwyczaj i jakby krwawe ${ }^{20}$.

Receptą na zażegnanie tych znaków były jednodniowe modły publiczne oraz dziewięciodniowe święto ofiar ${ }^{21}$. W dalszych latach nadal pojawiały się corocznie kamienne deszcze oraz pioruny ${ }^{22}$. Jak przekazuje Liwiusz w opisie wypadków lat 207-206 p.n.e., w którym po raz ostatni odnotowuje prodigia drugiej wojny

${ }^{14}$ Liv. 23, 31, 15: [...] ob quem imbrem novendiale, ut adsolet, sacrum fuit [...] [tłum. M. BRoŻEK]. Jest to zapewne odniesienie do pierwszego odnotowanego przez Liwiusza przypadku kamiennego deszczu, który miał miejsce po pokonaniu przez króla Tullusa Sabinów. Deszcz spadł na Górze Albańskiej, na którą wysłano obserwatorów, bo nie chciano dać wiary temu zjawisku. „W ich oczach spadło mnóstwo kamieni z nieba, jak gdy wiatry sieką ziemię gęstym gradem”. Liv. 1, 31, 1-4 [tłum. A. KościóŁeK]. Ostatnim odnotowanym prodigium tego rodzaju jest deszcz kamienny w Reate, Liv. 43, 13, 4: Reate imbri lapidavit.

${ }^{15}$ Liv. 24, 10, 6 [tłum. M. BrożeK].

${ }^{16}$ Liv. 24, 10, 10: Hadriae aram in caelo speciesque hominum circum eam cum candida veste visas esse.

${ }^{17}$ Liv. 24, 10, 6: et Calibus creta et Romae in foro boario sanguine pluisse.

${ }_{18}$ Liv. 24, 10, 9: tacta de caelo atrium publicum in Capitolio, aedem in campo Volcani, Vacunae in Sabinis publicamque viam, muru mac portum Gabiis.

${ }^{19}$ Liv. 24, 44,8: Murus ac porta Caietae at Ariciae etiam Iovis aedes de caelo tacta fuerat.

${ }^{20}$ Liv. 25, 7, 7-8: Tempestates foedae fuere; in Albano monte biduum continenter lapidibus pluvit; tacta de caelo multa, duae in Capitolio aedes, vallum in castris multis locis supra Suessulam, et duo vigiles exanimati; murus turresque quaedam Cumis non ictae modo fulminibus sed etiam decussae. Reate saxum ingens visum volitere, sol rubere solito magis sanguineoque similis [tłum. M. BROżEK].

${ }^{21}$ Liv. 25, 7, 9.

22 Liv. 26, 23: 211 r. p.n.e.; Liv. 27, 4: 210 r. p.n.e.; Liv. 27, 23: 209 r. p.n.e.; Liv. 27, 37: 208 r. p.n.e.; Liv. 28, 11: 207 r. p.n.e.; Liv. 30, 38: 202 r. p.n.e. 
punickiej, robiąc wyjątek tylko dla roku 202 p.n.e., w którym odbyła się rozstrzygająca dla losów całej wojny bitwa pod Zamą:

W społeczeństwie pełnym podniecenia wskutek tak wielkiego napięcia wojennego, gdzie wszystkie przyczyny powodzenia i niepowodzenia odnoszono do bogów, meldowano o wielu znakach wróżebnych ${ }^{23}$.

Same w sobie nie wpływały one bezpośrednio na wynik starć wojennych, jednak były z nim sprzężone poprzez powiększanie atmosfery strachu, a nawet grozy panującej w pierwszych latach pobytu Hannibala w Italii oraz pod koniec wojny, co doskonale oddaje zdanie Liwiusza o stawiających opór Kartagińczykach w roku 202 p.n.e. i znakach wróżebnych, które „dodawały ludziom strachu”24. Ów ogromny strach jest odczuwalny podczas lektury dzieła Liwiusza, nawet jeśli nie był to strach prawdziwy, a jedynie groza stworzona, czy też powiększona, przez antycznych historiografów.

Najbardziej znanymi odniesieniami pogodowymi związanymi z drugą wojną punicką jest przejście Hannibala przez Apeniny ${ }^{25}$, bitwa pod Kannami 216 r. p.n.e., do której zaraz wrócę, oraz o pięć lat późniejsza próba zdobycia Rzymu w 211 r. p.n.e. Według wyważonego opisu Liwiusza próba ta w Ab Urbe Condita wyglądała tak:

Następnego dnia Hannibal przekroczył rzekę Anio i wyprowadził do bitwy wszystkie siły. Również Flakkus i konsulowie nie cofnęli się przed rozprawą. Po obu stronach stanęły wojska w szykach bojowych do spotkania, w których nagrodą zwycięzcy miało być miasto Rzym, ale potężna ulewa $z$ gradem takiego narobiła zamieszania w obu liniach walczących, że ledwie utrzymano broń w rękach i zdołano się schronić do obozu niczego nie bojąc się mniej niż przeciwnika. Podobnie nazajutrz w tym samym miejscu taka sama burza rozdzieliła ustawione do boju linie. Natomiast gdy wracano do obozu, pojawiła się dziwnie piękna pogoda i cisza w powietrzu. Punijczycy wzięli to za znak boski, a Hannibal, jak podają, powiedział, że do zdobycia Rzymu raz mu nie jest dany rozum, to znowu szczęście ${ }^{26}$.

${ }^{23}$ Liv. 28, 11 [tłum. M. BrożeK].

${ }^{24}$ Liv. 30, 38, 8: prodigia quoque nuntiata sub ipsam famam rebellionis terrorem adtulerant.

${ }^{25}$ Liv. 21, 58.

${ }^{26}$ Liv. 26, 11: postero die transgressus Anienem Hannibal in aciem omnes copias eduxit; nec Flaccus consulesque certamen detractauere. instructis utrimque exercitibus in eius pugnae casum in qua urbs Roma uictori praemium esset, imber ingens grandine mixtus ita utramque aciem turbauit ut uix armis retentis in castra sese receperint, nullius rei minore quam hostium metu. et postero die eodem loco acies instructas eadem tempestas diremit; ubi recepissent se in castra, mira serenitas cum tranquillitate oriebatur. in religionem ea res apud Poenos uersa est, auditaque uox Hannibalis fertur potiundae sibi urbis Romae modo mentem non dari, modo fortunam [tłum. M. BrożEK]. 
Florus, dla którego Epitome Liwiusz był głównym źródłem, rozbudowuje ten opis, dodając aparat bogów i retoryczną przesadę:

Dlaczego więc dziwimy się, że Hannibalowi ustępującemu z odległości trzech mil zagrodzili drogę sami bogowie, mówię bogowie i nie będę się wstydził tego wyznać? Przy każdym bowiem jego ruchu spadły tak wielkie potoki deszczu, powstały tak silne wiatry, że wróg ustępował dzięki boskiej pomocy zesłanej, jak się zdawało, nie z nieba, lecz z murów samego miasta i z Kapitolu. Przeto uciekł, ustąpił i wycofał się do najdalszego zakątka Italii, byleby tylko pozostawić to miasto, któremu oddawał prawie boską cześćc ${ }^{7}$.

Owe wielkie potoki deszczu połączone z potężnymi wiatrami dla niektórych historyków są raczej opadami gradu, bo choć w tekście pojawia się vis imbrium, to słowo imber może oznaczać „deszcz”, „ulewę” jak w przekładzie Ignacego Lewandowskiego, ale także „burzę śnieżną i gradową"28.

Epitomator nazywa odpędzenie Hannibala od murów Rzymu „życzliwością bogów" (tanto favore etiam deorum). Bogów, którzy w osobie Jowisza - rozpętują pod murami Rzymu burzę w Punica Syliusza Italika. W tym epickim poemacie w 17 księgach o drugiej wojnie punickiej Syliusz opisuje próbę kartagińskiego szturmu na Rzym, nadając mu specyficzny koloryt w ciemnych, ponurych barwach, wykorzystując zjawiska atmosferyczne oraz wpisując w zdobywanie Rzymu literacki topos burzy ${ }^{29}$, występujący w epice od czasów Odysei Homera, zazwyczaj jednak jest to burza na morzu. Trzy zdania Liwiusza rozpisuje na ponad 150 linijek i kilka etapów burzy, a więc pojawienie się inicjatora burzy, następnie wiatrów w odpowiedniej sekwencji, zapadnięcie ciemności, burzy z błyskawicami, przemowy bohatera oraz uciszyciela burzy. Co ciekawe, także Syliusz zsyła na Hannibala, nie tylko deszcz, ale i grad.

Tak więc Liwiuszowa trzyzdaniowa ulewa $\mathrm{z}$ gradem, rozwinięta w cały akapit przez Florusa, rozrosła się w epickiej wizji Syliusza do niebotycznych rozmiarów, rozwinęła w czasie i przestrzeni, wypełniając cały kadr obrazu narysowanego przez poetę w ponurej, ciemnej kolorystyce, i wzbogaciła w detale - dalsze zjawiska meteorologiczne, ich barwy i odgłosy.

${ }^{27}$ Flor. 1, 22, 44-46: quid ergo miramur moventi castra ab tertio lapide Hannibali iterum ipsos deos - deos inquam, nec fateri pudebit - restitisse? Tanta enim ad singulos illius motus vis imbrium effusa est, tanta ventorum violentia coorta est, ut divinitus hostem submoveri non a caelo, sed a urbis ipsius moenibus et Capitolio veideretur. Itaque fugit et cessit et in ultimum se Italiae recepit sinum, cum urbem tantum non adoratam reliquisset [tłum. I. LEWANDOWSKI].

28 S. LANCEL, Hannibal, tłum. R. Wiśniewski, Warszawa 2001, s. 207.

${ }_{29}$ Sil. It., Pun., 12.605-752. J.R. Telg, Hannibal ad portas: Silius Italicus, Punica 12,507-752. Einleitung, Übersetzung und Kommentar, Heidelberg 2018. 
Innym ciekawym zagadnieniem związanym z pogodą jest metaforyka meteorologiczna, którą posługiwał się w opisie początków drugiej wojny punickiej Florus $^{30}$, co być może jest twórczym rozwinięciem Liwiuszowej frazy ingentem illam tempestatem Punici belli ${ }^{31}$.

Pierwszym z pojawiających się w tekście Epitomy słów związanych ze zjawiskami natury jest tempestas ${ }^{32}$, a więc „burza”, „nawałnica” lub „sztorm”, używana także w znaczeniu przenośnym jako „rozruchy” czy „niepokoje” ${ }^{33}$. Według Florusa była ona "potężna i żałosna” ${ }^{34}$, a „grom od dawna już przeznaczony dla Rzymian rozpalił się od saguntyńskiego ognia" ${ }^{35}$. Błyskawica ta (fulmen) może być tu metaforą samego Hannibala, wielokrotnie w literaturze historiograficznej określanego mianem ognia, płomienia bądź błyskawicy - fax oraz ignis/pyr ${ }^{36}$ i noszącego przydomek Barkas, przez niektórych badaczy identyfikowany z greckim terminem keraunos $^{37}$.

Przejście Hannibala przez Alpy zostało poetycko określone jako opad metaforyczny, niespodziewany i nie do zatrzymania: „[nawałnica] niesiona jakimś silnym podmuchem przeleciała natychmiast przez środek Alp i spadła na Italię z owych śnieżnych szczytów o bajecznej wysokości, jak gdyby zesłana z nieba"38.

Metafory burzy w odniesieniu do spraw państwowych i państwa jako okrętu są częstym toposem. Liwiusz wkłada w usta Kwintusa Fabiusza Maksymusa taką przemowę dotyczącą wyborów konsula roku 214 p.n.e.:

Gdy morze jest spokojne, każdy żeglarz lub podróżny może sterować okrętem. Ale gdy sroga zerwie się burza, gdy wiatr zacznie miotać okrętem po szalejącym morzu, wtedy trzeba człowieka będącego prawdziwie sternikiem. My właśnie płyniemy nie po spokojnym morzu, lecz przeciwnie, już w kilku burzach omal nie poszliśmy na dno. Toteż z największą troską i przezornością musicie przewidzieć, kto ma siedzieć przy sterze ${ }^{39}$.

${ }^{30}$ Na ten temat szerzej: P. Matusiak, Tempestas Punici belli. Notes on Three 'Meteorological' Passages from Florus's Epitome of Roman History, „Scripta Classica” 2012, vol. 9, s. 75-79.

${ }^{31}$ Liv. 31, 10, 6.

${ }^{32}$ Flor. 1, 22, 9.

33 S.v. tempestas, [w:] Oxford Latin Dictionary, Oxford 1968, s. 1914.

${ }^{34}$ Flor. 1, 22, 9: gravis et luctuosa [tłum. I. LewANDowski].

${ }^{35}$ Flor. 1, 22, 9: destinatumque Romanis iam diu fulmen Saguntino igne conflavit [tłum. I. LEWANDOWSKI].

${ }^{36}$ Liv. 21, 10, 11: hunc iuvenem tamquam furiam facemque huius belli; Liv. 21, 3, 6: ne quandoque parvus hic ignis incendium ingens exsuscitet; Plut. Flam. 21, 7; Plut. Fab. Max. 2, 4.

${ }^{37}$ G. Charles-Picard, Hannibal, tłum. Z. Stein, Warszawa 1971, s. 14.

38 Flor. 1, 22, 9: [tempestas] statim quodam impetu rapta medias perfregit Alpes et in Italiam ab illis fabulosae altitudinis nivibus velut caelo missa descendit [tłum. I. LEWANDOWsKI].

${ }^{39}$ Liv. 24, 8, 12-13 [tłum. M. BRożEK]. 
Tak więc starcia z Hannibalem były kolejnymi burzami - co ciekawe, tłumacz tej części ksiąg Liwiusza, Mieczysław Brożek, wykorzystuje tę metaforykę, wybierając do polskiego przekładu słowo "nawałnica” nawet tam, gdzie Liwiusz użył vis, a więc „siła”, ale też militarnie „atak”, „uderzenie” czy o siłach natury „moc”, "potęga", „żywioł"40.

Rozwijając atmosferyczne porównania, Florus bitwę nad Ticynusem w $218 \mathrm{r}$. p.n.e. nazwał primi impetus turbo ${ }^{41}$, czyli „wichurą" bądź „huraganem” pierwszego uderzenia. Następującą po niej bitwę nad Trebią określił jako drugą burzę wojny punickiej ${ }^{42}$. Trzecia bitwa - tym razem nad Jeziorem Trazymeńskim w czerwcu 217 roku p.n.e. - była dla epitomatora znów piorunem, nagłym uderzeniem ${ }^{43}$, podkreślonym przez przysłówek subito (podobnie jak we wcześniejszych opisach sta$\operatorname{tim}^{44}$ ). Rozegrana 2 sierpnia 216 r. p.n.e. bitwa pod Kannami była dla Florusa raną - vulnus ${ }^{45}$. Historyk znalazł także tu miejsce dla opisu zjawisk atmosferycznych. Passus ten zawiera pochwałę kartagińskiego wodza, jego doświadczenia i zmysłu dowódcy, który sprawdził warunki terenu oraz pogody i jak najkorzystniej wykorzystał tą wiedzę ${ }^{46}$. Hannibal tak ustawił szyk bojowy, żeby mógł walczyć przy pogodnym niebie, z pomocą wiatru, do którego jego wojsko stało tyłem, kurzu i słońca, do których Rzymianie byli zwróceni twarzą. Wiatr ten był zwany volturnus, choć u Florusa pojawia się nazwa Eurus (jak podaje Lancel dzisiejsza nazwa wiatru to libeccio ${ }^{47}$, wiejąc Rzymianom prosto w oczy, przynosił ze sobą tumany kurzu. Z przekazu bizantyńskiego historyka z XII w., Jana Zonarasa, bazującego na niezachowanych dziś fragmentach Kasjusza Diona, możemy wysnuć wniosek, że to właśnie wiatr przechylił szalę zwycięstwa na korzyść Kartagińczyków:

[...] silny piaszczysty wicher, wiejąc prosto w oczy, utrudniał łapanie oddechu, co i tak stało się trudne, ze względu na nieprzerwany wysiłek. Pozbawieni zarówno wzroku, jak i głosu, Rzymianie polegli wśród paniki i braku porządku ${ }^{48}$.

${ }^{40}$ Liv. 21, 57, 1 .

${ }^{41}$ Flor. 1, 22, 10: primi quidem impetus turbo inter Padum atque Ticinum.

${ }^{42}$ Flor. 1, 22, 12: secunda Punici belli procella.

${ }^{43}$ Flor. 1, 22, 13: Trasymennus lacus tertium fulmen Hannibalis.

${ }^{44}$ Flor. 1, 22, 9; 1, 22, 10.

${ }^{45}$ Flor. 1, 22, 15: Quartum id est paene ultimum volnus imperii Cannae.

${ }^{46}$ Flor. 1, 22, 16: callidus imperator in patentibus campis, observato loci ingenio, quod et sol ibi acerrimus et plurimus pulvis et Eurus ab oriente semper quasi ad constitutum, ita instruxit aciem, ut Romanis adversus haec omnia obversis secundum caelum tenens vento pulvere sole pugnaret.

47 S. LANCEL, Hannibal..., s. 166.

${ }^{48}$ Zon. 9, 1, 14. Przekład [w:] A. Lewandowski, P. Matusiak, „O Kanny, Kanny”. Bitwa pod Kannami według Zonarasa (9, 1, 9-16), „Scripta Classica” 2019, vol. 16 [w druku]. 
Frontynus w rozdziale poświęconym wyborowi miejsca bitwy również precyzuje, że Wolturnus wiał w usta i oczy ${ }^{49}$, a więc odbierał Rzymianom widok jak w opisie Liwiusza ${ }^{50}$, oddech oraz głos ${ }^{51}$. Natomiast Zonaras dodaje, że przed bitwą Hannibal „zaorał najpierw” piaszczysty teren, co dodatkowo miało spowodować unoszenie się przeszkadzających w walce chmur kurzu ${ }^{52}$.

Florus, konkludując tę część opisu zmagań rzymsko-kartagińskich, nie zawahał się napisać, z charakterystyczną dla niego retoryczną przesadą ${ }^{53}$, że Kartagińczyk w tej bitwie „na zagładę nieszczęsnego wojska [...] wszedł w zmowę z ziemią, niebem, światłem dziennym, słowem, z całą naturą" ${ }^{54}$.

Wszystkie te określenia - tempestas, procella oraz turbo - były używane metaforycznie na określenie zagrożenia, często wewnątrzpaństwowego, czego przykłady znajdziemy między innymi u Cycerona ${ }^{55}$. U samego Florusa termin tempestas pojawia się jeszcze trzykrotnie - raz na określenie wojny azjatyckiej ${ }^{56} \mathrm{i}$ dwa razy wskazując źródło rozruchów - raz Mariusza i dwukrotnie Sullę ${ }^{57}$. Posłużenie się jednak tak skondensowaną w opisie drugiej wojny punickiej metaforyką związaną ze zjawiskami atmosferycznymi pozwala z jednej strony urozmaicić narrację historyczną, z drugiej pokazać zaś, że pojawienie się Punijczyków było nagłe i zaskakujące, być może wywołujące strach i panikę, starcie z nimi gwałtowne i wymagające wielu sił, a ich pokonanie - tak jak i walka z burzą czy wiatrem - było poza zasięgiem Rzymian. Tekst Florusa jest przykładem, że w starciu armia kontra natura, nawet jeśli natura jest tylko metaforą, na dodatek wnoszącą - podobnie jak w prodigiach u Liwiusza - element grozy, najczęściej to właśnie ona jest górą. Według niektórych historyków ${ }^{58}$ dzieło Florusa jest w rzeczywistości panegirykiem narodu rzymskiego. Przegrana jedynie z siłami natury znakomicie się wpisuje w taką koncepcję historiografii.

${ }^{49}$ Front. 2, 2, 7 (de loco ad pugnam eligendo) oraz komentarz B. Burligi: Frontyn, Podstępy wojenne, przełożył, wstępem i przypisami opatrzył B. BurLiga, Wrocław 2016, s. 136, przyp. 170.

${ }^{50}$ Liv. 22, 46, 9: prospectum ademit.

${ }^{51}$ Zon. 9, 1, 14.

${ }_{52}$ Zon. 9, 1, 9. Cf. A. Lewandowski, P. Matusiak, „O Kanny, Kanny”. Bitwa pod Kannami wedtug Zonarasa (9, 1, 9-16), „Scripta Classica” 2019, vol. 16 [w druku].

${ }_{53}$ Warto zaznaczyć, że w nowożytnych badaniach istnieje podział na koncepcję historiografii „retorycznej” („Izokratejskiej”) oraz „tragicznej”. Florusa moglibyśmy umiejscowić w tej pierwszej, a Liwiusza w drugiej koncepcji. S. ŚNIEŻEWsKI, op. cit., s. 87-88; 102-103, przyp. 20.

${ }^{54}$ Flor. 1, 22, 15: Ibi in excidium infelicis exercitus dux, teraa, caelum, dies, tota rerum natura consensit [tłum. I. LEWANDOWsKi].

${ }_{55}$ Cic. Dom. 137: tu, procella patriae, turbo ac tempestas pacis atque oti (Cyceron do Klodiusza w mowie De domo sua ad haruspices, wygłoszonej w roku 57 p.n.e.).

${ }^{56}$ Flor. 1, 24, 8: Asiatici belli mota tempestas.

${ }^{57}$ Flor. 1, 47, 12: inde Mariana, inde Sullana tempestas; Flor. 2, 13, 2: Sullana tempestas.

${ }^{58} \mathrm{Na}$ ten temat: I. LewANdowski, Historiografia rzymska, Poznań 2007, s. 349; E. GRYKsA, Obraz Rzymu u Florusa, Tarnów 2017, s. 117-123. 


\section{Patrycja Matusiak}

\section{THE ROLE OF WEATHER IN THE NARRATIVE OF THE SECOND PUNIC WAR}

Summary: The purpose of the article is to present the role of natural weather phenomena that were noted by ancient historians in the narrative of the Second Punic War (218-201 BC). In addition to the best-known use of the weather during the Battle of Cannae (216 BC), during which Hannibal, according to historian Florus, colluded with all nature, the article analyses the failed attempt to capture Rome in 211 BC - prevented by a storm, weather prodigia heralding Roman defeat in the first part of the war as well as the function of meteorological battle imagery.

Keywords: Second Punic War, Hannibal, weather, storm, prodigia. 